Cómo citar este artículo en MLA: Arcila Rojas, Claudia. "La escritura y la lectura: un proceso dialéctico para el conocimiento”. Escritos 28. 60 (2020): 79-92. doi: http://dx.doi.org/10.18566/escr.v28n60.a08

Fecha de recepción: 01.04 .2020

Fecha de aceptación: 10.06 .2020

\title{
La escritura y la lectura: un proceso dialéctico para el conocimiento ${ }^{1}$
}

\author{
Writing and Reading: Dialectical Process for Knowledge
}

\author{
Claudia Arcila Rojas ${ }^{2}$
}

\begin{abstract}
RESUMEN
En la apresurada afirmación de que la escritura es un testamento que concentra el patrimonio de la intención de un ausente, se ha generalizado la idea de la inmutabilidad del texto que responde y obedece a un criterio de coherencia en el cual, el tratamiento de su idea fluye sin el atisbo de obstáculos atribuibles a una perspectiva hermenéutica que le sugiere plasticidad a la escritura y, por consiguiente, apertura creativa y propositiva a la lectura. Frente a esta problemática que restringe el carácter dialéctico del lenguaje, la apuesta conceptual que a continuación se plantea tiene como objetivo cuestionar el criterio de objetivación lingüística por separar a la palabra de su naturaleza reflexiva en sintonía con la referencia al ente que moviliza en sus significados. El alcance dinámico de la escritura admite que la lectura acontezca como un apéndice de la observación que no solamente se prepara cognitivamente al análisis del conjunto de grafemas que se integran para mostrar por medio de las palabras, sino que debe apropiarse sensorialmente de la imagen que le expresa sus atributos y alteraciones al lenguaje como vínculo imprescindible en todo acto de enunciación. En este sentido, la ruta conceptual marxista se trenza con un panorama filosófico crítico con el que cobra vigencia la relación dialógica entre texto y lector en un movimiento de la mirada hacia el corazón mismo de la pretensión expositiva, a fin de pedagogizar el encuentro con el texto mediante un enfoque hermenéutico crítico guiado por el paradigma cualitativo. Bajo esta forma, se puede sintetizar que la resignificación de la escritura comporta su connotación de textura dinámica permeable por los interrogantes que favorecen nuevos y sorprendentes hallazgos en la humana y loable tarea de conocer la materia. Esto supone comprometer la palabra, tanto oral como escrita, con nuevos retos de indagación que hacen del conocimiento una experiencia en continua mutación.
\end{abstract}

Palabras clave: Escritura; Lectura; Dialéctica; Conocimiento; Investigación; Diálogo; Significado; Pedagogía.

1 El presente artículo se deriva de la tesis doctoral: "Una mirada desde el prisma filosófico de José Ortega y Gasset a la figura poética de Simón Bolívar en "Mi delirio sobre el Chimborazo".

2 Doctora en Filosofía. Docente Investigadora Universidad de Antioquia, Colombia. Miembro del grupo de investigación Somos palabra: Formación y contextos de la Universidad de Antioquia. Correo electrónico: claudiarbol@gmail.com. 


\begin{abstract}
Because of the rushed statement that writing is a testament that concentrates the intention of someone who is absent, the idea of the immutability of text has been generalized. The latter is associated with a criterion of coherence in which the realization of the idea flows with no obstacles. Regarding this issue, which limits the dialectic nature of language, this article offers a conceptual alternative that aims at questioning the criterion of linguistic objectivation because it separates the word of its reflective nature, which is in tune with the reference to the entity that drives its meanings. The dynamic reach of writing makes possible for reading to become an appendix of observation, which not only prepares cognitively for the analysis of the set of graphemes, but that also must appropriate sensorially the image that expresses its attributes and alterations as a necessary link in every act of enunciation. Thus, the Marxist conceptual route is linked to a critical philosophical standpoint in which the dialogical relation between text and reader takes effect within a movement of looking towards the heart of the purpose. The latter is done with the aim of making more pedagogical the meeting with the text through a critical hermeneutical approach. To sum up, the resignification of writing implies considering it as a permeable and dynamic texture due to the questions that foster new and surprising findings in the endeavor of knowing. This also means that word, both oral and written, should be linked to new challenges for questioning, which makes of knowing an experience in constant change.
\end{abstract}

Keywords: Writing; Reading; Knowledge; Research; Dialogue; Meaning; Pedagogy.

\title{
Introducción
}

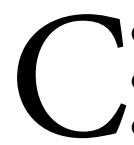

on el propósito de suscitar el debate frente a la diferenciación apreciativa del lenguaje escrito como un legado de imperturbables declaraciones y, un sondeo terminológico que se acerca en campo abierto a la aprehensión de rasgos y datos de la naturaleza y la sociedad en su condición cambiante, se plantea, desde esta reflexión teórica en el marco de las apreciaciones lingüísticas del marxismo, la consideración de la escritura como un cuerpo dinámico que vibra y se modifica por el seguimiento y transcripción del objeto que la ocupa.

En el lenguaje escrito, muy a pesar de la subordinación que le declara Saussure, al afirmar que "la escritura vela y empaña la vida de la lengua" (79), se contienen todas las manifestaciones humanas que intentan interrogar el sentido de lo bello, lo bueno y lo verdadero y sus contrarios, presentes en todo lo existente; el sentido de lo dialéctico que se encuentra en el cosmos y en la vida, como movimientos configurándose y reconfigurándose hacia nuevos eventos de ordenada, estética y contingente manifestación; eventos que, por lo demás, logran retratarse como imagen mental, pero también divulgarse por medio de la palabra y de su rigor argumentativo, tan moldeable y susceptible de arreglos, como el arte mismo, puesto que la escritura, por ser experiencia de lectura atraviesa una especie de muerte que convierte el lenguaje en una obra haciéndose y rehaciéndose en la combinación de expresiones:

La metáfora de la muerte y la resurrección, de la vida póstuma, o de la vida después de la vida es común en relación con la lectura, como si la letra encarnara el espíritu y lo mantuviera animado hasta que el lector le diera, en cada lectura, una nueva vida en su propio interior (Larrosa 63).

Es por ello que la acción creadora del arte alcanza identidad con la acción compositora del lenguaje, puesto que él es la exteriorización de todas las cosas que pasan por el hilo de la comprensión, es decir, la coseidad trasciende su lugar de imagen como estímulo meramente sensorial, a experiencia acaeciendo lingüísticamente $y$, por ende, aportando datos a la conciencia con el fin de darle apertura al suceso cognitivo. Por ello, ver es la afectación sensible hacia el saber; la vista, afirmó Aristóteles en el libro 
primero de la Metafísica, (3) es el sentido que le otorga al hombre un conocimiento más amplio y detallado de las cosas pero que, se hace saber al poderse "mostrar precisamente mediante el decir" (Heidegger \& Fink 26). No en vano, insiste Heidegger "poner y decir se refieren a lo mismo con una misma manera de hacer-aparecer" (¿Qué significa pensar? 198).

Por lo anterior, la escritura se sustenta en la mutabilidad de sus elementos, combina colores y formas para materializar la textura de sus expresiones, pero sin clausurar la definición del orden que se ha hecho imagen y semántica de un momento de la realidad y de la psicología humana, momento que se captura y se prolonga en el discurso, estimulando a que el lenguaje escrito evolucione en explicación y en pregunta hacia nuevas búsquedas del conocimiento. Sabido es "que no hay ciencia que pueda desarrollarse y prosperar sin lucha de opiniones, sin libertad de crítica" (Stalin 29) y sin renovación permanente de sus enunciados, pues de lo contrario estaría confinada al dogmatismo y la hechicería, antes que al carácter argumentativamente fluido de sus teorías:

La geología invalida la tesis cristiana de la edad del mundo; la astronomía invalida la del geocentrismo; la psicología la del libre albedrío; el naturalismo darwiniano, la del origen divino del hombre; la astrofísica la tesis del origen creacionista del mundo, y así sucesivamente (Onfray, "Cosmos" 359).

En este devenir, en el que el conocimiento es una posibilidad siempre renovada y renovadora de la palabra $y$, por consiguiente, de toda doctrina teórica, es importante indicar que, hasta la misma comprensión que se tenga sobre la dialéctica ha de exponerse al tratamiento dinámico que implica el método dialéctico. Afirma Guadarrama (2006), en el prólogo al libro El realismo dialéctico en la historia, que la dialéctica es un "insustituible instrumento de desarrollo de todo lo existente incluyendo la concepción que se tenga de ella misma y hasta su propio crítico pensamiento" (23). De esta manera, la praxis investigativa encuentra en el horizonte dialéctico las fuentes dialógicas para conocer la naturaleza, la sociedad y el hombre: "concebidos como criaturas históricas, esto es como sujeto y objetos de un incesante proceso de creación y recreación" (García, 97) y, por lo mismo, de una práctica actualizada de enunciación; es decir, de un discurso oral y escrito atento al dinamismo creativo y recreativo de todo lo existente.

\section{Desarrollo del tema}

Tras la aseveración de que el discurso constituye un puente entre los hombres y sus experiencias, se atisba el movimiento incesante de la vida como un reclamo solicitando el diligenciamiento de los cambios, avatares y contradicciones valiéndose del despliegue de las múltiples formas narrativas, estilísticas, de contenido y de forma del lenguaje (Martínez-Salanova 51). Es por esto que la escritura concede este discurrir lingüístico con un elevado grado de actividad, dado que cumple simultáneamente con dos etapas cognitivas de preponderancia en el hecho del pensamiento: memoria e identidad son los pilares racionales y emocionales a partir de los cuales la escritura transmite y transcribe el suceso pragmático de la existencia devenida materia de contradicciones y ajustamientos, y por lo mismo, herencias socioculturales que no hacen ajena la racionalidad de la emocionalidad (Maturana 33).

De igual modo, la escritura también ajusticia los célebres encumbramientos de la mentira dejados como evocación inalterable que se recita y se transita en la palidez de una verdad inmóvil; una afirmación o negación contraria a la esencia de lo real, a sus ondulaciones y giros tendientes a denunciar la construcción 
de la historia como evento mancomunado entre el hombre y su derecho y testamento simbólico que constituye la transición de lo visual a lo abstracto, pues, "lo que es verdad para el espacio, lo es también para el tiempo" (Greene 84) y para la palabra que expresa la capacidad retentiva que el lenguaje contiene al actualizar y elevar el objeto inaprehensible, en un momento dado, por los sentidos.

La escritura tramita en el vocabulario las caracterizaciones de un momento de la realidad presentado como objeto tangible o psicológico; es decir, como contenido sensorial o mental desde el cual el lenguaje se nutre para apoyar el oleaje indagativo y compositivo del pensamiento: "Todos los lenguajes tienen su propio sistema de retroalimentación que les convierte en procesos vivos" (Martínez-Salanova 50); eventos que gravitan en las dinámicas ideológicas, tecnológicas, epistemológicas para hacer del lenguaje un cuerpo de manifestaciones y evidencias del cambio. La escritura se enriquece en el destello de fenómenos que concurren en el universo, adoptando "un considerable número de nuevas palabras y expresiones" (Stalin 2), de tal manera que las nuevas apariciones que sufre un objeto o un contexto, comprometen a la escritura con movimientos y acercamientos semánticos que no distorsionen las leyes sustentadas en la gramática. Por eso, la escritura como composición de sentido, apropiación y valoración del suceso que describe, no ha de estar desligada de una fuente ordenada que, en la lógica de la manifestación cambiante, plantea una secuencia en la sistematización, conforme a lo cual la escritura es reflejo de verdad apuntalada del antecedente sensorial.

De esta manera, en la montura galopan no solamente los significados, sino también los significantes dentro de un incesante fluir de palabras, definiciones y expresiones dispuestas a componer el sendero del discurso, y por tanto, a reflejar o retratar los pasos que ese sendero va adoptando como huellas narrativas del acontecer simbólico de los hombres y de su identidad lingüística: "La identidad construida en la lectura, en la memoria, en el tiempo es una identidad narrativa" (Mèlich 49) que pone en escena el mundo y su unidad en permanente expresión de fuego y extinción, como lo plantea Heráclito (63); ese mundo que se conoce en el suceder permanente de las palabras: "Una frase no tiene sentido completo hasta que cada palabra, una vez pronunciadas sus sílabas, da lugar a la siguiente" (De Aquino 102).

Desde este horizonte, los relatos son elevamientos lingüísticos que se apoyan en la existencia y aparición de los objetos a los sentidos y experiencias humanas, hallando en la sociedad y la cultura una nueva geografía filológica expandiéndose y comprimiéndose en su naturaleza exponencial y argumentada de las palabras, las cuales peregrinan al unísono con la actividad humana, puesto que:

(...) la lengua está directamente ligada a la actividad productora del hombre, lo mismo que a todas sus demás actividades en todas las esferas de su trabajo, sin excepción. A ello se debe que el vocabulario, por ser lo más susceptible de cambiar, se encuentre en un estado de transformación casi incesante (Stalin 22).

A la luz de este dinamismo, las relaciones que los hombres sostienen con las cosas y con los demás hombres, redactan el nivel histórico de sus construcciones artísticas y culturales, y al mismo tiempo, el acontecer histórico de sus relaciones políticas, económicas y sociales que, en su unidad, definen el andamiaje ideológico predominante en una comunidad.

Ahora bien, el concepto de comunidad encierra lo común que alcanza su evidencia en la comunicación, puesto que esta pone de manifiesto las prácticas y enunciaciones, a partir de las cuales aparecen convergencias e identidades que universalizan principios desde una colectividad de sentidos articulados en la gramática y la lógica de lo humanamente deseable. 
Constituyen estos principios el punto de apoyo de las distintas rutas y reivindicaciones populares; es decir, la columna vertebral y argumentativa de la existencia exenta de las tergiversaciones que la sociedad clasista impone para dividir y subjetivizar las acciones y los anhelos humanos. Justa y dignamente se ennoblece la intencionalidad humana hacia su experiencia de habitabilidad del mundo; libremente se ambiciona el paso y el acceso por el ámbito de los derechos que no pueden limitarse a denotar el vacío de su posibilidad, sino la condición real de su materialización. Por ello, los grabados del lenguaje son "huellas escritas en las palmas de las manos: grietas definitivas en la mirada" (Álape 17) capaces de comprender el devenir de la naturaleza y de la historia desde las expresiones más simples de sus alcances, logrando con esto hacer del conocimiento la expresión consecuente de lo que acontece pues "el propio conocer, como proceder anticipador, se instala en un ámbito de lo ente, en la naturaleza o en la historia" (Heidegger, "Caminos de bosque" 77). Un ámbito en el que "Lo vivo, es uno, único y modificado de maneras diversas" (Onfray, "Cosmos" 307) y, por ende, con el deber de ser narrado en atención a dicha diversidad.

De ahí que la prescripción de la vida como una experiencia de movimiento tenga que estar amparada por la solidez argumentativa de su realización, debido a que el aspecto ético de su ley sustenta el fundamento gramatical que le da origen a nuevos principios exclamativos de las relaciones sociales y vinculantes del lenguaje por mediación de la cultura y su posibilidad de tejer "relaciones internas entre los conceptos que hagan posibles los 'descubrimientos gramaticales' (...) de un sentido de la localización en el espacio dialéctico o en el tiempo histórico” (Rorty 163).

En este sentido, la lengua es expresión de los componentes cosmológicos contenidos en concepciones políticas, jurídicas, económicas, sociales, culturales y epistemológicas, equivalentes a la transcripción del orden operante y construido; es decir, al de la naturaleza y al de la sociedad, en vista de que la existencia de la lengua es fruto de la creación de los miembros de la sociedad para favorecer la interlocución entre ellos; de ahí que su pertinencia sea "precisamente para que sirva a la sociedad, considerada como un todo, de medio de relación entre los hombres" (Stalin 4) como canal de acuerdos y críticas que favorezca la continuidad en el tiempo de sus prácticas y creencias.

Pero este nivel de comprensiones colectivas no puede relevarse de la consideración material y dialéctica de la existencia porque, en ellas, el ser y el hacer humano posibilitan la contemplación real y necesaria de nuevos ciclos históricos y físicos conducentes a la apropiación certera y equilibrada de recursos, valores y principios cualitativos que trazan los saltos de la evolución.

Por ello, todo hallazgo es, en realidad, un progreso producto de la actividad humana que intenta, desde el lazo indisoluble entre lenguaje y pensamiento, impactar positivamente la sociedad entendida como el conjunto de "las partes con relación al todo y lo simple con relación al compuesto" (De Aquino 44), construyendo mejores condiciones de habitabilidad y aprovechamiento de los recursos, de la técnica y los insumos que el hombre emplea para dignificar su trabajo.

De ahí que el lenguaje sea la manifestación de un dato que el universo expone para ser dilucidado, y en esa medida aprovechado por el hombre, y no solo como patrimonio de conocimiento que posibilita dominar las fuerzas de la naturaleza, sino además, como modelo gramatical que propone un orden justo y dinámico en las relaciones humanas. Justamente por esto, la lengua, como disposición fáctica de la enunciación oral y escrita, conserva y privilegia unas particularidades que la diferencian y le atribuyen leyes en su avance. La lengua pues 
(...) sirve a la sociedad como medio de relación entre los hombres, como medio de intercambio de ideas en la sociedad, como medio que permite a los hombres entenderse mutuamente, y organizar el trabajo conjunto en todas las esferas de la actividad humana, tanto en la esfera de la producción como en la esfera de las relaciones económicas, tanto en la esfera de la política como en la esfera de la cultura, tanto en la vida social como en la vida privada. Estas particularidades son exclusivas de la lengua, y precisamente porque son exclusivas de la lengua, esta es objeto de estudio por una ciencia independiente: la lingüística. Si la lengua no tuviera estas particularidades, la lingüística perdería el derecho a una existencia independiente (Stalin 34).

Atender la compleja marca que va dejando la lengua en la sociedad, solicita la atención científica que ha de considerar su objeto en un ambiente tan cambiante y ensombrecido como el que constituye la sociedad, en un ambiente intervenido y matizado por la circulación de distintos factores causantes de fenómenos antagónicos y conflictivos que apremian del respaldo de la palabra para el reconocimiento de sus detalles y efectos: "Hay que contar siempre con la evolución de las sociedades y sus formas de expresión, que corresponden a cambios ideológicos y filosóficos, a movimientos políticos, a modas, a desastres naturales, a guerras o al paso del tiempo" (Martínez-Salanova 50).

Por ser el crecimiento de la sociedad el resultado de la confluencia de elementos políticos, económicos y simbólicos, se torna más envolvente el desempeño del lenguaje puesto que en él, su ruta oral o escritural es recorrida por el sujeto hablante que puede llegar a otorgar "diferente significado a unas mismas palabras y expresiones en dependencia de la clase a que pertenezca" (Stalin 38), desmintiendo el suelo gramatical que valida el despliegue y repliegue del vocabulario para concretar la palabra, pero además, ensombrecer la esencia humana puesto que, "solamente el habla capacita al hombre ser aquel ser viviente que, en tanto que hombre, es" (Heidegger, "De camino" 11). Es claro entonces, que

(...) el vocabulario adquiere una importancia enorme cuando se halla a disposición de una gramática, que establece las reglas que rigen las modificaciones de las palabras y la combinación de las palabras en oraciones y, de este modo, hace de la lengua algo armónico y coherente. (...) Por tanto, gracias precisamente a la gramática, la lengua obtiene la posibilidad de dar a los pensamientos humanos una envoltura lingüística material (Stalin 20-21).

En este proceso que da cuenta de las dimensiones cognitivas y emocionales que el hombre opera con la materia, el lenguaje, al constituirse como puente de acercamiento entre los hombres y la existencia, ha de estar soportado por unas leyes de inquebrantable rigor lógico, encargadas de fundamentar todo acto lingüístico como enunciación que alude o se corresponde con un componente de la materia que debe instalarse sintácticamente para alcanzar la dilucidación de su esencia. Pero de esta ley gramatical se desprende la ley semántica y su impronta para que toda "conversación (siga) la misma regla, pues se sirve de sonidos portadores de un significado" (De Aquino 102) y, de esta manera, continúa impulsado por el orden inherente al objeto en una inexorable secuencia expresiva que transcribe el comportamiento del ente movido en el lenguaje, de tal modo que la marca lingüística muta continuamente en sintonía con la cosa que se compone y recompone tanto en su existencia como en la palabra, tanto en su manifestación real, como en su apropiación simbólica y en su carácter de representación, aunque es clara la acotación de que "nada permanece en la oscuridad después de consultar la partida de nacimiento de una palabra" (Onfray, "Cosmos" 53). No obstante:

El lenguaje se transforma -y transforma- constantemente en nuestras sociedades, ofreciendo a la especie humana abundantes recursos para sus investigaciones y para el intercambio cultural, haciendo evolucionar 
tanto los sistemas sociales, de interrelación, como los educativos y políticos. La visión actual del mundo y de la especie humana pugna con los propios valores, poniendo en el solfa los conocimientos que se van acrecentado acerca de la propia realidad humana y de su incierto futuro. Los diferentes lenguajes son a la vez vehículo de cultura y producto cultural, por lo que se genera una dialéctica intrínseca a la sociedad, a la que la sociedad no puede ser ajena (Martínez-Salanova 51).

Por ello, el lenguaje tiene un asiento lúdico desprendiendo grafemas, fonemas y conceptos que juegan entre los intersticios del silencio, dispuestos a entonar los vocablos que expresan una nueva forma o aparición en la verdad que se cumple en el ente, la misma naturaleza expone este sentido vibrante, puesto que ella:

existe más allá del bien y del mal, conlleva tanto vida como muerte, nacimientos como decesos, solidaridad como perjuicio, instinto maternal como pulsión de muerte, hembras que paren y amamantan como machos que devoran a sus hijos y arrasan el nido, la madriguera, el territorio de sus semejantes (Onfray, "Cosmos" 159).

La palabra se mueve en el objeto, en los fenómenos y circunstancias que componen estas vibraciones; se acomoda a sus ondulaciones, repliegues y explosiones para ser fiel con su propósito de conocer el orden dinámico que lo constituye y reconstituye. La palabra deambula al ritmo del movimiento del objeto, así como el pensamiento sucumbe en el oleaje lingüístico para devenir en textura de los hilos fonéticos y gráficos que elevan en significado y significación el significante y sus eventualidades.

Se moldea la semántica en la dinámica del caos al cosmos y viceversa, transita del devenir del objeto en fenómeno y se filtra en los polos antagónicos y complementarios para registrar sus detalles; es como un río fluyendo al choque de piedras y corrientes que enriquecen su pausa en aguas más serenas, pero, donde nuevos vientos y tormentas aceleran su nacimiento en territorios más tibios, pero vertiginosos; en el territorio de la vida con sus múltiples y diversas apariciones:

El mundo, la naturaleza, las aves, el río, las flores, la luna y el sol, los peces, las plantas, los bosques, las planicies, los perros, las luces, los colores, las estaciones, las ranas, los niños, los ratones, las libélulas no son sino variaciones de un único y mismo tema: el cosmos (Onfray, "Cosmos" 381).

De ahí entonces que el carácter argumentativo del lenguaje deba cumplir con unas condiciones lingüísticas que muten sin desmentir sus leyes, es decir, que sean versátiles en atención al objeto y sus circunstancias, pero que además se reconozcan y se identifiquen con unas columnas gramaticales que cohesionan y depuran el suceso epistemológico de la composición, pues "la palabra no es un fin en sí mismo, sino un medio para alcanzar algo más y mucho mejor que la palabra: captar una de las epifanías del mundo del modo más brillante (Onfray, "Cosmos" 381).

Con este planteamiento, el lenguaje, como materia prima del pensamiento, caracteriza a la lengua con su idiosincrasia, enunciando y fluyendo discursivamente sobre un terreno morfológico que contiene en sí mismo la lógica, el rigor y la belleza que le concede seriedad a sus divulgaciones y comprensiones:

Directamente ligada al pensamiento, la lengua registra y fija en palabras y en palabras combinadas en oraciones los resultados del trabajo del pensamiento, los progresos de la actividad cognoscitiva del hombre, y, de esta forma, hace posible el intercambio de ideas en la sociedad humana (Stalin 21). 
Pero esta labor lingüística no está viciada por una connotación sesgada de la lengua. Ella, desde sus mismos pilares gramaticales, guarda justicia en la composición de los enunciados, puesto que exterioriza la situación de un objeto y su relación con el ambiente circundante, atendiendo a una naturaleza vinculante entre los sujetos hablantes de carácter gnoseológica, en vista de que se eleva como concepto el objeto, es decir, se lo asciende a enunciación pero sin inmovilizarlo en sus alcances cambiantes y en su esencia dialéctica; sin atender a los criterios de "una civilización que no ha dejado de castrar, de desvitalizar y luego de disecar y embalsamar" (Onfray, "Cosmos” 122).

Este propósito dinámico lo alcanza el lenguaje puesto que él deja fluir en su manifestación oral y escrita, la perfección y su desvanecimiento en la textura dialéctica que cobija a la naturaleza, a la sociedad y al mismo pensamiento dentro de unos principios que consideran el orden como un episodio continuamente renovándose y enriqueciéndose en el opuesto acontecer de sus particularidades, contrario a los criterios ideológicos de control y regulación de las palabras, los cuales constituyen "una forma política de mantener o de modificar la adecuación de los discursos, con los saberes y los poderes que implican" (Foucault 37) y, conforme a ellos "se inculca una forma de ver el mundo, de enfocar lo real, de pensar las cosas" (Onfray, "Antimanual" 129).

En este orden de ideas, la escritura es como la experiencia del artista que usa sus sentidos para comunicarse con la naturaleza y hacerla insumo de su historia y realidad, de sus búsquedas y expectativas tornando más entrañable la relación con el lenguaje que ha superado lo dogmático para darle lugar al imponente e importante aporte de la fantasía, pues ella inspira y susurra nuevas comprensiones frente al universo. La fantasía cuenta con disposiciones cognitivas beneficiadas por el caudal idiomático y gramatical guardando conformidad con el principio de realidad, es decir, con la materia viviente y con sus posibles transformaciones, simbolizando y representando otro estado de la vida que rompe con el tiempo occidental de la línea recta para comprender el "tiempo circular de las estaciones, tiempo cíclico del cosmos, tiempo de la rueda oriental" (Onfray, "Cosmos" 388) que también mueve el presente hacia un vínculo de diálogo con el pasado y con el futuro. Por ello "El lenguaje tiene siempre algo que está más atrás que el lenguaje mismo" (Roig 5): un tiempo pretérito y proyectivo de la materia palpitante que constituye la realidad que ha de ser significada.

Por esta razón, si la historia es cambio continuo ha de presuponerse que la ciencia sobrelleva también esta mutación, pero no como desgracia o penalidad, sino como incentivo a la combinación de nuevas palabras que intentan el pulimiento y realización de la obra; pero esta fatalidad, por lo que parece perderse en la memoria un legado que significó certezas alrededor de prácticas y ritos definiendo un período de la existencia, es realmente una inmensa riqueza de variados componentes manifestando la vibración de lo que enuncian: "El desarrollo incesante de la industria y de la agricultura, del comercio y del transporte, de la técnica y de la ciencia exige que la lengua enriquezca su vocabulario con nuevas palabras y expresiones necesarias para su trabajo" (Stalin 8 ).

En este sentido, la plasticidad del lenguaje obedece, en primera instancia, a su elevado grado de sensibilidad ante la materia, pues el lenguaje no solamente atiende la referencia estética contenida en la gramática del universo, sino también, los asimétricos encumbramientos que la naturaleza y la sociedad ofrecen en su contingente devenir de sucesos. Todo espacio de manifestación lingüística constituye un tiempo en su aparición que su fuerza oscila en la esencia del movimiento que engendra el cambio y, por consiguiente, nuevas apreciaciones y sentimientos de interlocución. 
De esta manera, el lenguaje, en su oralidad y en su escritura, renace continuamente cuando es fiel a su condición aprehensible del mundo, cuando enaltece el objeto en la idea visual o sonora que no desatiende los vientos y fricciones que alteran la objetivación de la cosa en su aislamiento y pureza nominal, antes bien, la vicia, en el auténtico sentido de conferirle el roce de su entorno con sus aires y desaires componiendo insumo de nuevos fenómenos circulados coherentemente en el lenguaje que, de igual manera se deja alterar por el devenir y sus antagónicos aires para mover sus estructuras de significación hacia los códigos del significante. Pero el lenguaje, así concebido, ha de ser la morada de un sujeto dispuesto y capaz de comprender y asumir su conexión de vitalidad y conciencia con el mundo, haciendo de su palabra un puente con la experiencia; un sujeto a favor y en expresión de la vida, con un cuerpo en gnoseología sensitiva:

(...) un cuerpo que huele, mira, saborea, goza del mundo, experimenta lo real, captura el detalle y la globalidad de la naturaleza, del cosmos, la palabra al servicio de la vida empírica, una fenomenología minimalista para una poética maximalista, una proposición estilística ínfima capaz de producir el sentimiento de lo sublime, una iluminación de lo que es (Onfray, “Cosmos” 386).

Así mismo, esta metamórfica condición que le subyace a la discursividad vigilante de un componente de la naturaleza, ha de estar sustentada en el carácter expositivo del lenguaje, es decir, en su disposición a exteriorizarse sin el revestimiento absolutista de arrogancias teóricas que parecen inmunes a la problematización de sus entidades explicativas. La lengua, al ser el "producto de toda una serie de épocas, en el curso de las cuales se cristaliza, se enriquece, se desarrolla y se pule" (Stalin 5) ha de reconsiderar la representación de coherencia como un estatuto de secuencia narrativa inmune a las regresiones que corrigen o atisban nuevos rasgos del objeto llevado a tesis. El verdadero acento lingüístico está guiado por la lógica que, en el caso concreto de la escritura, es imprescindible como espacio que reserva páginas para el registro del suceso dialéctico en el tratamiento del objeto que se adjetiva y se divulga en un escenario de interacción con otros objetos.

Pero para esta consideración, la lectura debe comprenderse como una percatación sensorial del objeto que no es simplemente narrado, sino que narra en su condición dinámica. Es manifiesta, por la experiencia y el lugar del lector frente al texto, la confrontación dialógica que se nutre en preguntas y pausas de reflexión y análisis a partir de la lógica en la composición orientando y asesorando el recorrido por la lectura y las búsquedas y observaciones simultáneas que conceden un encuentro más amplio con la escritura y, por tanto, más íntimo con la tesis que plantea.. El lector estará así facultado para indagar distintas fuentes y territorios físicos y lingüísticos que incentiven al más cercano encuentro con el objeto en cuestión.

Por todo ello, la lectura remite a la composición de los vínculos que, de manera cotidiana o planeada, se dan entre los hombres y su entorno; ella es filtro que cierne las enunciaciones y definiciones que logran con mayor fidelidad transparenciar el mundo y su apetencia al ocultamiento: "a la naturaleza le place ocultarse" (Heidegger \& Fink 394). El lector entonces no puede entenderse sin una actitud de asombro y sin una prioridad interrogativa, pues es sabido que él cumple las veces de productor y portador de conocimiento que, mediante la palabra, reflexiona y convoca a las discusiones que hacen comprensible un saber sobre el mundo de la vida, del cosmos y de sus cambios.

Desde esta perspectiva, cobra validez el encuentro de diálogo entre texto y lector, pero superando la figura de espejo de la escritura, pues en ella reposa la silueta de la subjetividad siempre dispuesta a justificar cualquier ángulo de aprehensión semántica. Antes bien, de lo que se trata es de trasladar la mirada 
del lector en una experiencia de enseñanza y aprendizaje hacia la pretensión de análisis en el unísono de las vibraciones objetivas que le otorgan vitalidad y lozanía a la palabra convencida del reto de ser y hacerse metáfora en la concepción de metamorfosis dentro de un mundo permanentemente cambiante y cambiantemente estético. Lector y escritura conjugan un encuentro de intimidad, y las palabras son linterna y brújula de nuevas manifestaciones y territorios por comunicarse. Son la materialización de la mirada que funge como baúl de la cultura y como puente de retorno al pasado y a sus tradiciones. No en vano, la cultura es "el saber de la naturaleza, el conocimiento del cosmos, la ciencia de la tierra" (Onfray, "Cosmos" 340-341) y, por consiguiente, el legado de la materia que convoca a que la escritura y la lectura sean gestos de permanente artesanalidad del lenguaje; un componer y construir los sentidos que le otorgan al conocimiento su carácter social en el compromiso de continuar uniendo voces para el cultivo de la tierra: "Uno no vive ni puede sobrevivir si no sabe dónde, cuándo y cómo plantar, sembrar, desmalezar, layar, curar, cosechar, arar. En esta configuración primitiva, el no saber lleva a lo peor: la escasez, el hambre, la muerte de los suyos" (Onfray, "Cosmos" 340). El no saber es un acto de indiferencia con la vida.

Por este movimiento en el campo de la gnoseología, como auténtico territorio del conocimiento que alberga los saberes remotos y los venideros, lo susceptible de ser conocido se torna cada vez más interesante y complejo, más consciente con la cultura, comprendida como "saber necesario para la agricultura" (Onfray, "Cosmos" 340);más responsable con el acto transformador del trabajo y dignificante de las acciones humanas, puesto que lo indagado no agota su afluencia de caracterizaciones mientras pasa de manera inmediata por la experiencia del ocultamiento. La naturaleza cambiante de la materia implica, a su vez, su condición finita de estados. Es por este aspecto que no se debe desatender el flujo mismo del conocimiento como antecedente resuelto y evidentemente contrastado por las nuevas observaciones, pues "la historia no hace nada esencial sino existe una necesidad particular" (Stalin 6) que estimule a vaticinar impactos que autoricen aprovechar justamente los acumulados científicos y cualitativos para que participen de la humana tarea de ayudar a romper los velos de la ignorancia disfrazada por las maquinarias comunicativas.

Cierto es que el florecimiento del vocabulario "con nuevas palabras, surgidas en relación con los cambios en el régimen social, con el desarrollo de la producción, el progreso de la cultura, de la ciencia, etc." (Stalin 22) representa el verdadero compromiso gnoseológico que le atribuye al lenguaje un desempeño imparcial frente a los distintos fenómenos sociales, pero fundamentalmente coherente y ético sobre sus bases gramaticales que son, a su vez, referencias de los órdenes físico e histórico dispuestos a ser simbolizados en el devenir del lenguaje.

La estructura gramatical de una lengua cambia aún más lentamente que su caudal básico de voces. La estructura gramatical, elaborada a lo largo de varias épocas, y siendo, como es, carne de la carne y sangre de la sangre de la lengua, cambia más lentamente todavía que el caudal básico. Naturalmente, sufre cambios en el curso del tiempo, se perfecciona, mejora y precisa sus reglas, se enriquece con nuevas reglas, pero las bases de la estructura gramatical subsisten durante un período muy largo, ya que, como lo demuestra la historia, pueden servir eficazmente a la sociedad en el transcurso de muchas épocas (Stalin 23).

La evidencia de este rasgo sustancial lingüístico está dada en la escritura que es susceptible de reportar el patrimonio terminológico como una herencia permanentemente renovada en su semántica, pero fundamentalmente estable en su gramática; cohesionada y regida por una estructura de lógica coordinación y ubicación de sus elementos. La filosofía reseña este dato y contribuye con la asimilación de la conversión como algo inherente a la unión de lo perfecto y lo imperfecto sobre la base del dialéctico 
devenir de las cosas, como un fluir de vida que congrega la totalidad para conocerla también en sus particularidades. Así se halla y se estimula la indagación, como un incentivo propio que centellea en su esencia, pero empieza a desenvolverse en su pertenencia a una condición más amplia.

Con todo, desde el primero y más básico acto de habla que lo constituye la descripción, se ha podido constatar que todo hecho enunciativo antes que reclamar coherencia, como reiterativa atribución de datos al objeto en composición, lo que realmente exige es la lógica, entendida como condición nominal que agrupa las significaciones que un significante expone en su interacción con otros significantes. El mundo de las cosas, así como el mundo de los hombres, no está constituido por apariciones aisladas, son ante todo construcciones de un orden dialéctico, en cuya esencia el movimiento convoca y compromete a los sentidos a ser depositarios de nuevos eventos lingüísticos hacia la composición del discurso que guarda en su condición la prioridad de ir cuestionando, aprendiendo y reconociendo las formas de encuentro y exploración de su medio para alcanzar a identificar, mediante la escritura, diferentes expresiones de la naturaleza y la sociedad y así, convertirlas en motivos de reflexión y construcción de pensamientos, entendiendo siempre que en el "devenir se oculta un orden, una lógica interna, unas leyes que lo organizan y relacionan los antecedentes con los consecuentes” (Farre 40).

Desde este ángulo, las palabras guardan, pero también comparten los colores y las formas de lo real, pues en su componer no solo proponen, sino que además muestran dentro de una clara intención de actualizar la vida y los estímulos que la hacen única e intransferible. Por ello, la palabra muta porque es además un legado existencial que narra en sus distintos géneros las herramientas que diferentes épocas y hombres tuvieron e inventaron para comprender su entorno; razón por la que ella sostiene y acompaña todas las rutas que el hombre sigue para acercarse al mundo y a las expectativas que frente a él ha creado; el lenguaje es el canto, el poema, la pintura, el tallado, el dibujo y el discurso dispuesto para que el hombre intente conocer y reproducir su ambiente, y no simplemente porque suscite un sentimiento de belleza, sino también la necesidad de desenvolverse en él como un aventurero registrando nuevos hallazgos. Tal vez por ello, el mismo lenguaje escrito sea el camino para hallar lo oculto, para descubrir y socializar el encuentro de una certeza universalmente válida que logre congregar emociones de complacencia y felicidad como estados de identificación de los seres humanos: identidad de la verdad dinámicamente ofreciéndose para ser narrada. Pero tal identidad "no es nunca una identidad que ofrece seguridad y certeza, por eso es ambigua y frágil. (...) es siempre provisional, plural, múltiple (Mèlich 62).

Ahora, la consolidación enunciativa, como acto de habla, constituye un hecho de conocimiento que ha de estar connotado como agente espía que no desatiende la aparición de nuevos sucesos en la naturaleza, la misma que, por lo demás, no guarda distancia con la concepción de materia, entendida como nominación abarcante de todo cuanto existe, incluido el hombre y las caracterizaciones culturales que fungen para el hecho ritual de la vida.

Solamente bajo esta chambrana epistemológica que resignifica la escritura como tejido inacabado y extendido a nuevos interrogantes, se hace consecuente una finalidad investigativa que aporte, de manera ética y honesta, una línea de la verdad continuamente configurando nuevos eventos de geométrica manifestación; nuevos rasgos geográficos que ponen a limitar la física y la historia en unas mismas fronteras de expansión.

Despejado pues el tribunal de las leyes del pensamiento se podrá recobrar en la escritura la versatilidad de sus composiciones, y no solo como un afincamiento de divulgación que coopere con el desmantelamiento 
del conocimiento, sino también como un portavoz auténtico de los nombres que las cosas confiesan para librarse de su anonimato. No basta con la contemplación de la vida en sus básicas referencias al movimiento, puesto que ella determina lo existente en una compleja red de leyes que transversalizan el mundo de la naturaleza, el mundo de los hombres y, estos traducidos en el mundo del pensamiento que evidencia su esfuerzo cognitivo en el habla y su radicación lingüística referida en la escritura. La vida es pues, el influjo del pensamiento que se deja atrapar por el lenguaje a fin de hacer real la conciencia en el contenido sensorial, dispuesto a impulsar y someter a la razón a una actitud de encuentro con el cosmos y con los conceptos que lo convierten en obra de observación.

La vida ronda la diversidad de lo existente para cumplir en él el propósito del tiempo, que no es otro que el de la transformación como sucesión cuantitativa y cualitativa de estados que proponen símbolos que deambulan hacia el signo de sus apreciaciones. Pero esos símbolos, como entes dotados de vitalidad, al amarrarse a la conciencia, admiten ser soltados en la palabra, como práctica estética, histórica y filosófica que alcanza a tocar el mito y la poesía con sus imágenes y sentidos, para luego ser filtradas, combinadas, seleccionadas y rectificadas para dar un salto evolutivo hacia la enunciación científica.

\section{Consideraciones finales}

En todo este proceder de la lingüística en la que la escritura y la lectura son concebidas como expresión dialéctica del conocimiento, el texto es el referente acumulativo de épocas y episodios que continúan encarando los nuevos comportamientos del cambio. "La estructura de la lengua, su estructura gramatical y caudal básico son el producto de varias épocas" (Stalin 24) y la herencia que sostiene las nuevas montañas de términos que se suman al paisaje de la lengua.

El posterior desarrollo de la producción; la aparición de las clases; la aparición de la escritura; el nacimiento del Estado, que necesitaba para la dirección una correspondencia más o menos ordenada; el desarrollo del comercio, que precisaba de ella todavía en mayor medida; la aparición de la imprenta, los progresos de la literatura: todo eso ocasionó grandes cambios en el desarrollo de la lengua. Durante este tiempo, las tribus y los pueblos se fraccionaban y dispersaban, se mezclaban y se cruzaban, y posteriormente aparecieron las lenguas nacionales y los Estados nacionales, se produjeron revoluciones, a los viejos regímenes sociales sucedieron otros. Todo ello introdujo cambios mayores aún en la lengua y en su desarrollo (Stalin 24).

En tal devenir histórico, natural y lingüístico, podría afirmarse que la lengua opera en un dinamismo crítico propio del acontecer dialéctico del conocimiento, que introduce, desde el estudio y la reflexión lingüística, un elemento interrogativo atento a cuestionar el ritmo de la lengua en sus materializaciones oral y escrita. Pero este interrogante ha de ser comprendido, a su vez, como una lente de los saltos cualitativos que marchitan una etapa para darle florecimiento a otra nueva.

Ciertamente:

(...) las lenguas no se han desarrollado destruyendo las existentes y creando otras, sino desarrollando y perfeccionando los elementos fundamentales de las lenguas existentes. Además, el paso de un estado cualitativo de la lengua a otro estado cualitativo no se ha operado por explosión, destruyendo de un solo golpe lo viejo y edificando lo nuevo, sino por acumulación gradual y prolongada de los elementos del 
nuevo estado cualitativo, de la nueva estructura de la lengua, por la extinción gradual de los elementos del viejo estado cualitativo (Stalin 24-25).

Desde esta perspectiva que nutre el impulso de la pregunta y sus aportes a las nuevas consideraciones que confrontan al lenguaje en su reflejo práctico de la conciencia, se entiende la construcción lingüística que se intenciona a llenar un vacío o a concretar una inconformidad, poniendo en duda cualquier cuerpo teórico o práctico que se propone generar certezas, absolutismos y anacronismos sin el auspicio de la razón y de su objetivo discernimiento. En la pregunta también se disipan los temores frente a distintas fuerzas físicas e históricas que parecían tener contenido divino, en cuyas revelaciones se signaba el destino de los hombres; la pregunta asalta la verdad acomodada en los púlpitos del sofisma y la demagogia, rompiendo los esquemas de la imposición para apelar a las directrices de la observación contrastada y constatada en la materia; en ella actúan de manera dialógica el análisis y la reflexión para verificar las apreciaciones aisladas y fragmentadas que pueden estar sugeridas por la actitud intimidante de sanciones y evaluaciones retardatarias.

La pregunta fluye, entre combinaciones y composiciones de letras que depuran el error para elevar las razones científicas, materiales y objetivas que rompen los velos del engaño, reconocido porque "se propone como meta encontrar en el mundo del perpetuo movimiento y de las perennes oscilaciones un punto muerto sobre el que poder sustentar el dogma inconmovible y sujetar el espíritu de la indagación y la crítica con las cadenas de hierro de la amonestación" (Konstantinov 17).

Por ello, en el espíritu de la pregunta y en su comprensión de premisa para la construcción científica, la actitud de vigilancia y búsqueda está siempre atenta a golpear la puerta del conocimiento con de las palabras que cristalizan lo desconocido o ausente en un reconocimiento de los nexos causales, a partir de la necesidad explicativa que incentiva una nueva inquietud para superar lo aparencial, en beneficio de la verdad continuamente retando el entendimiento a nuevos esfuerzos que controlan los límites de la hechicería, la superstición y sus silenciamientos.

A la luz de lo expuesto, por ser el lenguaje el terreno del pensamiento, y este, la expresión de la vida, la naturaleza y la sociedad, no puede concebirse la realidad cognitiva, es decir, el lenguaje como texto explicativo del cosmos, como una obra estática y digna de reverencia ya que, sin importar el influjo y destino de los pensamientos, ellos solo pueden "surgir y existir sobre la base del material idiomático, sobre la base de los términos y las frases de la lengua" (Stalin, 37) que son tiempo en el espacio de la materia, y finitud en su cambiante esencia.

\section{Referencias}

Álape Lascarro, Pastor. Tirofijo: los sueños y las montañas. Bogotá: Planeta, 2007.

Aristóteles. Metafísica. Lexington: Tecnibook Ediciones, 2013.

De Aquino, Santo Tomás. De los de la naturaleza. Buenos Aires: Aguilar, 1981.

Foucault, Michel. El orden del discurso. Barcelona: Tusquets, 1987.

Farre Galofré, Luis. Heráclito. Fragmentos. Buenos Aires: Aguilar, 1963.

García, Antonio. El realismo dialéctico en la historia. Bogotá: Ediciones Humanismo y

Sociedad Ltda., 2006.

Greene Randolph, Brian. El Universo Elegante. Barcelona: Drakontos, 2001. 
Heidegger, Martin. ¿Qué significa pensar? Buenos Aires: Ed. Nova, 1972.

Heidegger, Martin. De camino al habla. Barcelona: Ediciones del Serbal, 1987.

Heidegger, Martin. Caminos de bosque. Madrid: Alianza Editorial, 1996.

Heidegger, Martin y Eugen, Fink. Heráclito. Barcelona: Editorial Ariel S.A., 1986.

Konstantinov, Fedor. Objeto de la Filosofía. México: Ed. Grijalbo, 1965.

Larrosa, Jorge (2003). La experiencia de la lectura. Estudios sobre literatura y formación. México: Fondo de Cultura Económica.

Mèlich Sangrá, Jean. Filosofía de la finitud. Barcelona: Empresa Editorial Herder, S.A., 2001.

Maturana Romesín, Humberto. Emociones y lenguaje en educación y política. Chile: Dolmen Ediciones, 1997.

Martínez-Salanova, Enrique (2001). "El lenguaje vivo de los medios de comunicación. Un paso más para la lectura crítica". Comunicar: revista científica iberoamericana de comunicación y educación, Huelva, n. 17, p. 49-55, octubre. Disponible en: $<$ http://www.uhu.es/cine.educacion/articulos/lenjuaje_vivo_medios.htm $>$. Acceso en: 12 Jun 1998.

Onfray, Michel. Antimanual de Filosofía. Madrid: EDAF, 2005.

Onfray, Michel. Cosmos. Argentina: Editorial Paidós, 2016.

Roig, Andrés. Bolívar y la filosofía de la historia. Presentada al III Congreso Internacional de Filosofía Latinoamericana. Universidad Santo Tomás. Bogotá, 1984.

Rorty, Richard. La filosofía y el espejo de la naturaleza. Madrid: Ediciones Cátedra, S.A., 1989.

San Agustín. Confesiones. Barcelona: Altaya, 1993.

Saussure, Ferdinand. Curso de Lingüística General. Buenos Aires: Editorial Losada, 1945.

Stalin, Josif. El marxismo y los problemas de la lingüística. Pekín: Ediciones en Lenguas Extranjeras, 1976. 